\title{
Nanosecond and Femtosecond Laser Ablation of Brass: Particulate and ICPMS Measurements
}

\author{
C. Liu, X. L. Mao, S. Mao, X. Zeng, R. Greif, and R. E. Russo* \\ Lawrence Berkeley National Laboratory, Berkeley, California 94720
}

\begin{abstract}
Femtosecond and nanosecond lasers were compared for ablating brass alloys. All operating parameters from both lasers were equal except for the pulse duration. The ablated aerosol vapor was collected on silicon substrates for particle size measurements or sent into an inductively coupled plasma mass spectrometer. The diameters and size distribution of particulates were measured from scanning electron microscope (SEM) images of the collected ablated aerosol. SEM measurements showed that particles ablated using nanosecond pulses were single spherical entities ranging in diameter from several $\mathrm{mi}-$ crometers to several hundred nanometers. Primary particles ablated using femtosecond ablation were $\sim 100 \mathrm{~nm}$ in diameter but formed large agglomerates. ICPMS showed enhanced signal intensity and stability using femtosecond compared to nanosecond laser ablation.
\end{abstract}

Laser ablation combined with inductively coupled plasma mass spectrometry (ICPMS) is a practical method for direct solid sample chemical analysis. ${ }^{1-5}$ Significant improvements in this technology have led to numerous routine applications, especially in geochemistry. Efforts are still underway to study parameters such as wavelength, ${ }^{6 ; 7}$ gas ambient, ${ }^{8}$ and energy fluence ${ }^{9-11}$ for further improving accuracy and precision of analysis. The ablated aerosol particle sizes are believed to significantly influence analytical performance using ICPMS detection..$^{12-14}$ Chemical composition, entrainment, transport, and decomposition in the ICP

* Corresponding author: (e-mail) rerusso@lbl.gov.

(1) Russo, R. E.; M ao, X. L.; Liu, H. C.; Gonzalez, J.; M ao, S. S. Talanta 2002, 57, 425-51.

(2) Russo, R. E.; M ao, X. L.; M ao, S. S. Anal. Chem. 2002, 74, 70A-7A.

(3) Alexander, M . L.; Smith, M. R.; Hartman, J. S.; M endoza, A.; Koppenaal, D. W. Appl. Surf. Sci. 1998, 129, 255-61.

(4) Bililign, S.; Feigerle, C. S.; M iller, J. C. Appl. Surf. Sci. 1998, 129, 344-9.

(5) Yang, M.; Reilly, P. T. A.; Gieray, R. A.; Whitten, W. B.; Ramsey, J. M. J. Korean Phys. Soc. 1997, 30, 359-63.

(6) Gonzalez, J.; M ao, X. L.; Roy, J .; M ao, S. S.; Russo, R. E. J. Anal. At. Spectrom. 2002, 17, 1108-13.

(7) Russo, R. E.; Mao, X. L.; Borisov, O. V.; Liu, H. C. J. Anal. At. Spectrom. 2000, 15, 1115-20.

(8) Nakata, Y.; M uramoto, J.; Okada, T.; M aeda, M. J. Appl. Phys. 2002, 91, 1640-3.

(9) Shannon, M. A.; M ao, X. L. L.; Fernandez, A.; Chan, W. T.; Russo, R. E. Anal. Chem. 1995, 67, 4522-9.

(10) Borisov, O. V.; M ao, X. L.; Ciocan, A. C.; Russo, R. E. Appl. Surf. Sci. 1998 $129,315-20$

(11) Mao, X. L.; Ciocan, A. C.; Russo, R. E. Appl. Spectrosc. 1998, 52, 913-8.

(12) Yoo, J. H.; Jeong, S. H.; M ao, X. L.; Greif, R.; Russo, R. E. Appl. Phys. Lett. 2000, 76, 783-5

(13) Jeong, S. H.; Borisov, O. V.; Yoo, J. H.; M ao, X. L.; Russo, R. E. Anal. Chem. $1999,71,5123-30$ all are related to the size of the aerosol particles..$^{15-17}$ For ablation, 33 the laser wavelength and pulse duration play a dominant role in 34 defining the size, size distribution, and chemistry of the ablated 35 particulates. The goal of this work was to measure particles using 36 femtosecond and nanosecond laser ablation and establish correlations with ICPM S performance.

The use of femtosecond ablation to reduce thermal effects and minimize fractionation for chemical analysis has been tested, using both IR and UV pulses. ${ }^{18-22}$ By using the same laser energy and spot size (same fluence), ICPM S performance with femtosecond laser ablation showed improvements in intensity, precision, and accuracy. To further investigate these improvements, the basis of this work was to examine the relationship between the particle size distribution and ICPM S response using UV femtosecond and nanosecond laser pulses. B rass alloys were ablated with fixed laser parameters of fluence, energy, spot size, and wavelength; pulse duration was the only difference. Brass alloys are commonly chosen as samples due to the thermal volatility difference of copper and zinc. ${ }^{18-24}$ These alloys are ideal for studying effects of pulse duration on fractionation and signal stability using ICPM S. The ablated aerosols also were collected on silicon substrates for scanning electron microscopic (SEM) measurements of particle sizes.

\section{EXPERIMENTAL SECTION}

The experimental configuration is shown in Figure 1. Two lasers were used; a Nd:YAG laser with 6-ns pulse duration ( $\mathrm{New}$ Wave Research, Minilase II) and a Ti:sapphire laser with 150-fs pulse duration (Spectra-Physics, TSA 25). The wavelength of both lasers was adjusted to be $266 \mathrm{~nm}$. For the nanosecond $\mathrm{Nd:YAG}$ laser, the fourth harmonic of the 1064-nm fundamental produces 266-nm light. For the Ti:sapphire femtosecond laser, it was the

(14) Outridge, P. M.; Doherty, W.; Gregoire, D. C. Spectrochim. Acta, Part B 1996, 51, 1451-62.

(15) Guillong, M .; Kuhn, H. R.; Gunther, D. Spectrochim. Acta, Part B 2003. $58,211-20$.

(16) Horn, I.; Gunther, D. Geochim. Cosmochim. Acta 2002, 66, A341.

(17) Koch J.; Feldmann I.; J akubowski N.; Niemax K. Spectrochim. Acta, Part B 2002, 57, 975-85.

(18) Kuhn, H. R.; Gunther, D. Anal. Chem. 2003, 75, 747-53.

(19) Jaworski, R.; Hoffmann, E.; Stephanowitz, H. Int. J. M ass Spectrom. 2002, 219, 373-9.

(20) M argetic, V.; Pakulev, A.; Stockhaus, A.; Bolshov, M.; Niemax, K.; Hergenroder, R. Spectrochim. Acta, Part B 2000, 55, 1771-85.

(21) M ao, X. L.; Ciocan, A. C.; Russo, R. E. Appl. Spectrosc. 1998, 52, 913-8.

(22) Gagean, M .; M ermet, J. M. Spectrochim. Acta, Part B 1998, V53, 581-91.

(23) Chan, W. T.; Russo, R. E. Spectrochim. Acta, Part B 1991, 46B, 1471-86.

(24) Borisov, O. V.; Mao, X. L.; Fernandez, A.; Caetano, M.; Russo, R. E. Spectrochim. Acta, Part B 1999, 54, 1351-65. 


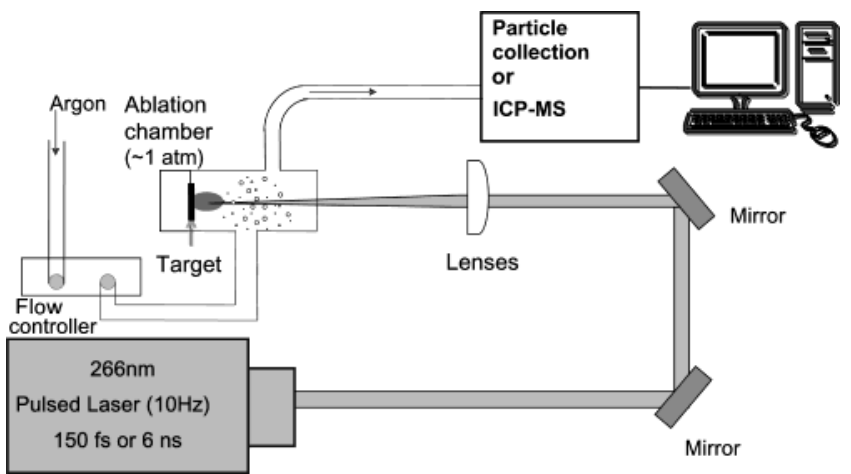

Figure 1. Experimental system. third harmonic of the 800-nm fundamental. Both lasers were operated at $10-\mathrm{Hz}$ repetition rate, at the same energy of $0.6 \mathrm{~mJ}$, and focused onto the sample surface using the same lens to a 66 $100-\mu$ m-diameter spot size. The fluence was $\sim 8 \mathrm{~J} / \mathrm{cm}^{2}$. The 67 irradiance was the only difference; for the nanosecond laser, it 68 was $1.3 \times 10^{9} \mathrm{~W} / \mathrm{cm}^{2}$ whereas for the femtosecond laser it was 569 $\times 10^{13} \mathrm{~W} / \mathrm{cm}^{2}$. The pulse-to-pulse energy stability (relative 70 standard deviation, RSD) of the femtosecond laser (5\%) was about 71 twice that of nanosecond laser $(2 \%$.

The ablated mass was transported out of the sample chamber 73 and collected for SEM measurements or delivered into the ICPMS. 74 Argon was used as the carrier gas. Ablation was continuous for 375 min for the ICPM S measurements (single spot on sample during 76 repetitive pulsing). The ICPM S (Thermoelemental, PQ3) was 77 operated at forward $\mathrm{rf}$ power of $1350 \mathrm{~W}$ with argon flow rates 78 of 14,1 , and $0.8 \mathrm{~L} / \mathrm{min}$ for coolant, auxiliary, and carrier, 79 respectively.

\section{1

8

9

.

\section{,} . . .
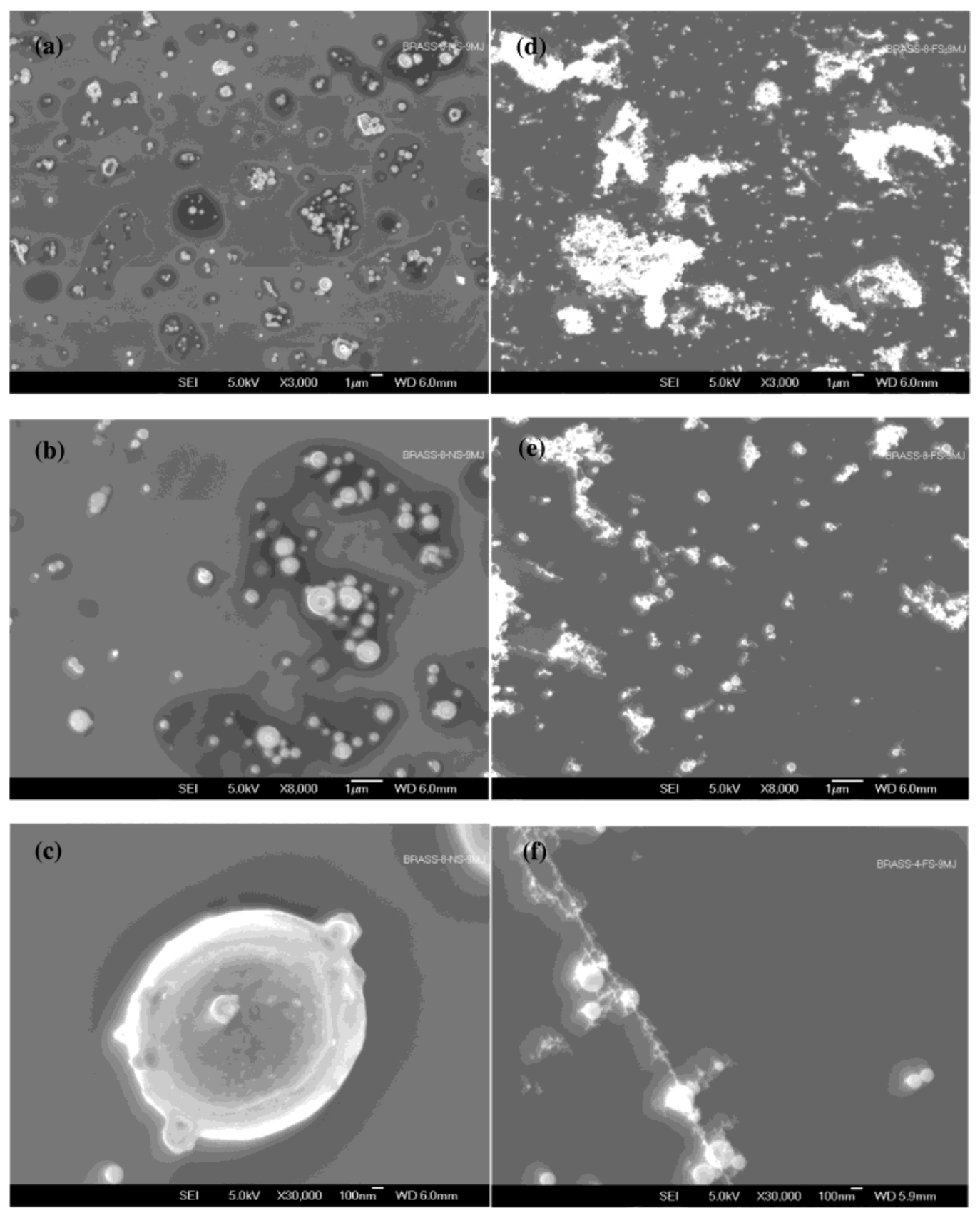

Figure 2. SEM images of ablated particles (a, b, and c from nanosecond laser ablation with $3000 \times, 8000 \times$, and $30000 \times$ magnification, respectively; $d$, e, and f from femtosecond ablation with $3000 \times, 8000 \times$, and $30000 \times$ magnification, respectively. 
SEM images were used to measure the shapes and sizes of particles collected on small clean silicon substrates. The same sample chamber and $1 \mathrm{~m}$ of tubing (the same tubing distance to the ICP torch) were used to transport the particles. For particle collection, the ablation time was $2 \mathrm{~min}$. The basis of the work was to qualitatively compare particles ablated using femtosecond and nanosecond pulses and establish relationships to ICPMS response, not to quantitatively define aerosol sizes and size distribution.

Brass with a $\mathrm{Zn} / \mathrm{Cu}$ ratio of 0.18 was used as the sample for particle and ICPMS measurements. However, a series of brass samples with zinc-to-copper mass ratios $(\mathrm{Zn} / \mathrm{Cu})$ from 0.06 to 0.65 were used to study the matrix effects on ablation sampling using both femtosecond and nanosecond pulses. ${ }^{65} \mathrm{Cu}$ and ${ }^{66} \mathrm{Zn}$ signal intensities were recorded sequentially using 10-ms dwell time for the quadrupole mass spectrometer. The volumes of the ablated craters in brass were measured using a white-light interferometric microscope (Zygo, New View 200). Three crater measurements were made for each set of experiments, and the RSD was $\sim 10 \%$ in volume.

\section{RESULTS AND DISCUSSIONS}

SEM. SEM images of particles collected at the exit of the ablation chamber and tubing are shown in Figure 2. The particle shapes and sizes were visually very different. Femtosecond ablation produced smaller particles that formed large agglomerates compared to large particles and small agglomerates from nanosecond ablation. Large agglomerates of irregular shape with sizes of 5-10 $\mu \mathrm{m}$ across (Figure $2 \mathrm{~d}$ ) existed from femtosecond ablation compared with smaller agglomerates from nanosecond ablation (Figure 2b). Particles from nanosecond laser ablation were mostly single spherical entities with diameters ranging from tens to thousands of nanometers (Figure $2 \mathrm{c}$ ). The large particle agglomerates from femtosecond ablation consisted of primary particles with size of $\sim 100-200 \mathrm{~nm}$, connected by filaments having dimensions of several nanometers. There were no single large droplets such as those observed with nanosecond ablation. The shape of the agglomerates connected by filaments is indicative of strong charge during the formation of these particles.25,26 It is not likely that the agglomeration was formed at the silicon surface but during transport. Particle agglomeration is related to size; smaller particles have a higher tendency to agglomerate than larger ones, supporting the SEM measurements.

The differences in particle sizes are related to the differences in femtosecond and nanosecond ablation. Melting and melt ejection should be prominent for nanosecond ablation. Particles as large as several micrometers in diameter are likely ejected from the molten sample surface due to recoil pressure of the expanding plume. The effect of melting is readily observed on the crater profiles in Figure 3. The craters were produced using the same number of pulses from each laser. Nanosecond ablation leaves a raised rim around the crater perimeter that is caused by resolidification of molten brass. M elting and splashing were reduced using femtosecond pulses consistent with the absence of a rim. The crater volume from femtosecond ablation was much larger ( $10-$

(25) Webb, R. L.; Dickinson, J. T.; Exarhos, G. J. Appl. Spectrosc. 1997, 51, 70717.

(26) Gravel, J.; Nobert, P.; Gravel, J. Y.; Boudreau, D Anal. Chem. 2003, 75, $1442-9$.

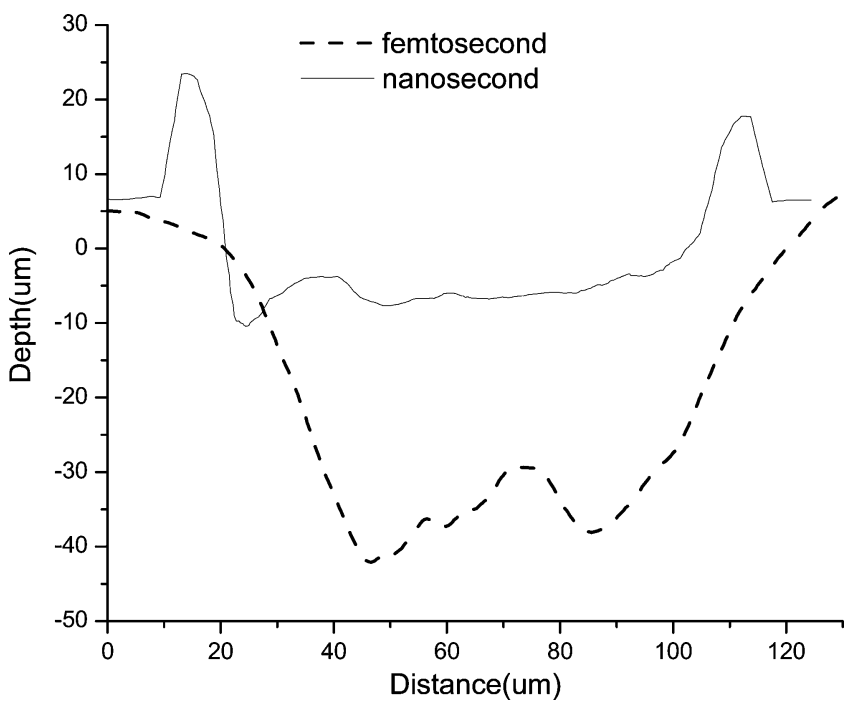

Figure 3. Crater profiles after 50 pulses each from nanosecond and femtosecond ablation of brass.
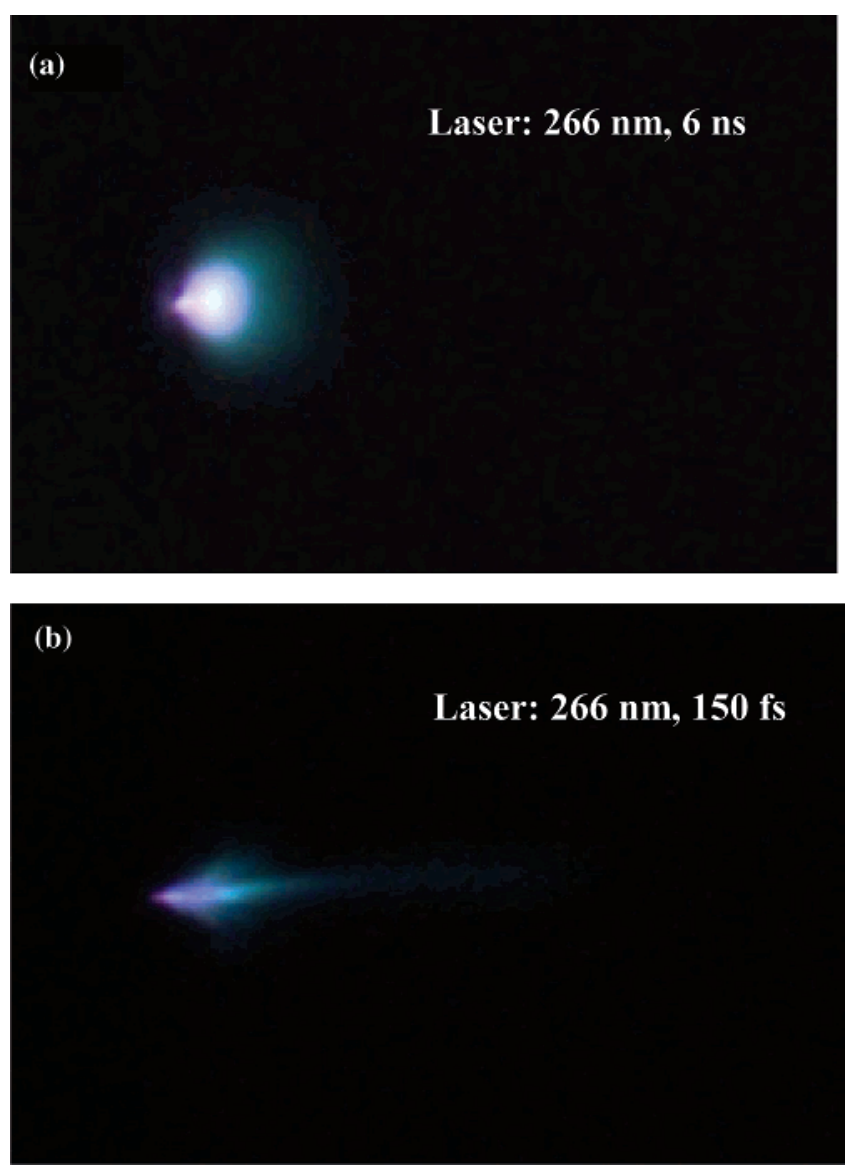

Figure 4. Photographs of laser plasmas from nanosecond and femtosecond ablation.

15 times) than from the nanosecond case, demonstrating improved ablation efficiency. Photographs of laser-induced plasmas support the probability of different particle formation mechanisms (Figure 4). For equal energy and spot size (fluence), the plasma from nanosecond ablation was spherically shaped while the femtosecond-induced plasma was cylindrical.

ICPMS. Brass was ablated (crater formation at a single spot) using both lasers while recording the signal intensity in the 

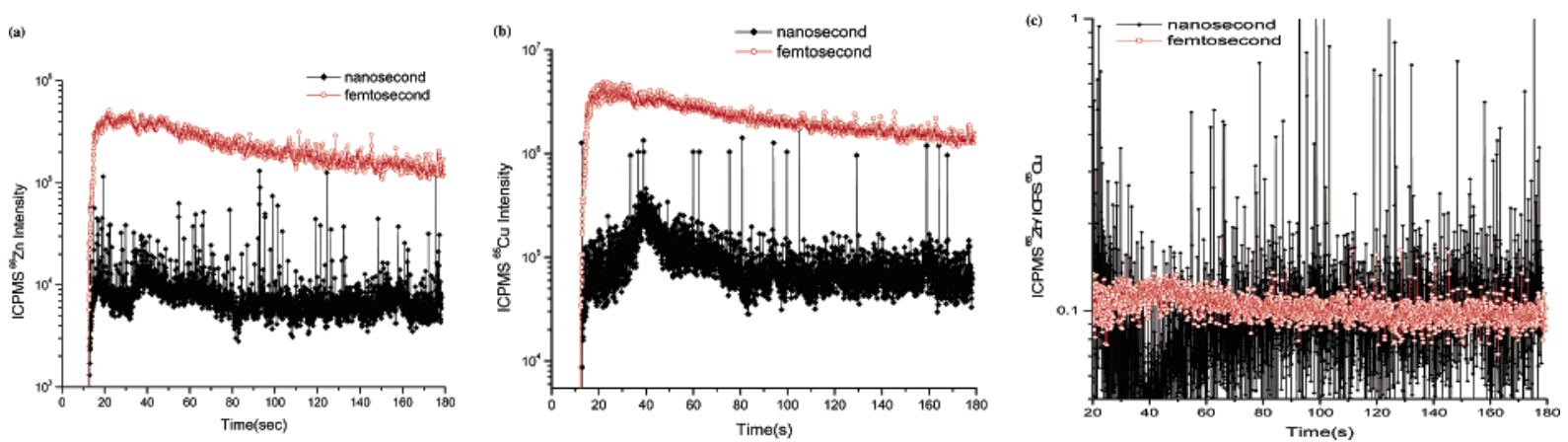

Figure 5. ICPMS intensity of ${ }^{66} \mathrm{Zn}$ and ${ }^{65} \mathrm{Cu}$ and ratio of ${ }^{66} \mathrm{Zn} /{ }^{65} \mathrm{Cu}$ with different pulse durations.

ICPM S; the temporal intensity for ${ }^{65} \mathrm{Cu}$ and ${ }^{66} \mathrm{Zn}$ are shown in Figure $5 \mathrm{a}$ and $\mathrm{b}$, respectively. Femtosecond ablation produced $\mathrm{Zn}$ and $\mathrm{Cu}$ elemental signals that were more than 10 times greater than produced by nanosecond ablation at the same fluence. The increase in ICPM S intensity is consistent with the volume data shown in Figure 3. An exact correlation between volume and intensity is not expected as the particle size and distribution differences will influence transport efficiency. The femtosecond data also showed less fluctuations (improved precision, RSD) and minimal spiking. The improved RSD in the femtosecond data exists even though the laser itself has poorer pulse-to-pulse stability. Instantaneous spikes with intensity of 10 times larger than the continuous level were measured for nanosecond ablation with overall larger intensity fluctuations (RSD) in the continuous signal. The spikes and precision are related to the particle size distribution from the ablation process. Nanosecond ablation produced larger particles and a larger particle size distribution (cf. Figure 2). Although femtosecond ablation led to agglomeration of smaller particles, the large agglomerates appear to be effectively digested in the ICP compared to single large particles. In principle, large particles should not transport as efficiently as smaller ones. However, the agglomerates may not behave as single entities during transport and in the ICP.

The smaller particle size distribution and improved signal stability from femtosecond ablation enhance analysis as demonstrated by the ${ }^{66 \mathrm{Zn} /}{ }^{65} \mathrm{Cu}$ ratio in Figure $5 \mathrm{c}$. The ratio for nanosecond ablation ranged from 0.05 to 0.2 , excluding the spikes on data. The ratio was significantly improved for femtosecond ablation $\left({ }^{66} \mathrm{Zn} /{ }^{65} \mathrm{Cu}=0.11\right.$ ) and was constant during the entire sampling period.

Six brass samples with $\mathrm{Zn} / \mathrm{Cu}$ ratios varying from 0.06 to 0.65 were ablated using both lasers. The calculated RSDs from the integrated temporal ( 1200 pulses for each sampling period) signal response are shown in Figure 6. For nanosecond ablation, the RSD was as large as $120 \%$ and matrix dependent, compared to femtosecond ablation, which showed smaller RSD values of $\sim 10 \%$ and independent of the zinc/ copper ratio. Optical and thermal properties of the sample influence the laser ablation process, especially using nanosecond pulses. For brass, zinc is more volatile than copper and can be significantly enhanced in the aerosol using nanosecond ablation. ${ }^{24}$ Lower zinc intensity from nanosecond ablation of low zinc concentration brass is not the cause of the increased error. For all the brass samples, the zinc intensity from nanosecond ablation was well above the background ( 200

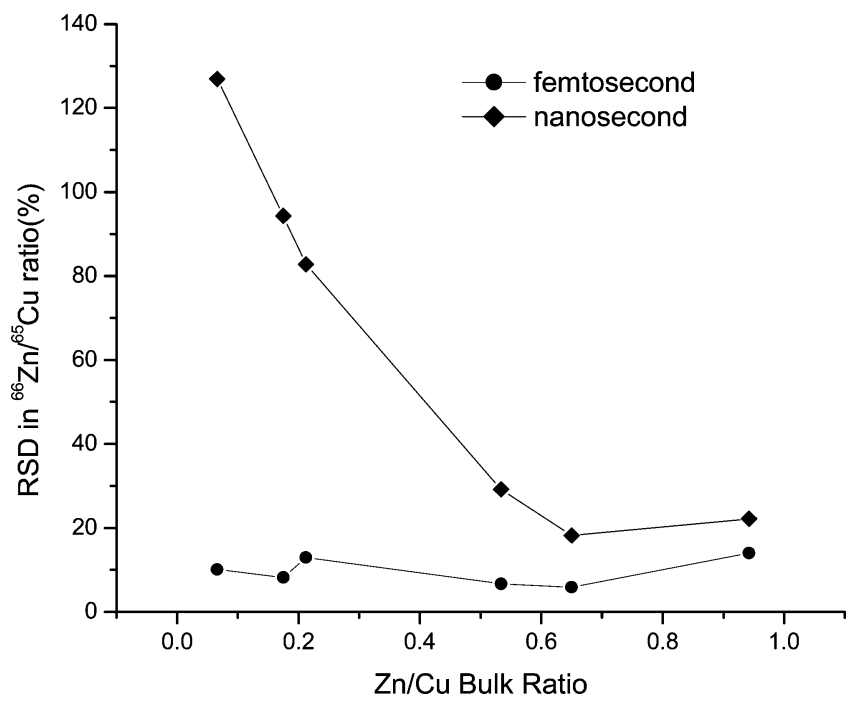

Figure 6. $\mathrm{RSD}$ with respect to bulk $\mathrm{Zn} / \mathrm{Cu}$ ratio.

counts). For similar zinc intensities, the error was significantly larger from nanosecond versus femtosecond laser ablation.

\section{CONCLUSION}

The particles formed from femtosecond and nanosecond laser ablation had a significant influence on the ICPMS response. Femtosecond laser ablation produced large agglomerates composed of small and narrowly distributed diameter particles while nanosecond ablation generated a wide size range of particle sizes, some as large as several micrometers in diameter. The smaller particles from femtosecond ablation lead to enhanced signal intensity and stability in the ICPMS. Spikes on the ICPMS response from nanosecond ablation represent the large particle size distribution. Melting and melt flushing are believed to be prominent mechanisms during nanosecond ablation as evidenced by the raised crater rim and large spherical particles in the aerosol vapor. The large agglomerates composed of nanometer diameter particles from femtosecond ablation were transported and digested by the ICPMS. Work is underway to establish the mechanisms for particle formation for femtosecond ablation; it is possible that the prominent mechanism may be nucleation and condensation of vapor.

$M$ atrix effects were reduced using femtosecond ablation; the sampling precision for a wide range of brass alloy composition was independent of the matrix composition. In addition, the 
$\mathrm{Zn} / \mathrm{Cu}$ ratio was stable throughout the sampling period in which a crater was formed. Such behavior has not been observed using nanosecond ablation. Improved precision and elimination of spikes makes the use of femtosecond ablation encouraging for chemical analysis applications.

\section{ACKNOWLEDGMENT}

The U.S. Department of Energy, Office of Basic Energy Sciences, Division of Chemical Sciences, and the Office of
Nonproliferation and National Security (NA22) supported this research at the Lawrence Berkeley National Laboratory under Contract DE-AC03-76SF00098.

Received for review September 4, 2003. Accepted October 222 30, 2003.

AC035040A 